\title{
Effects of Grit on the Academic Performance of Medical Students: A Cross-Sectional Study at Majmaah University
}

This article was published in the following Dove Press journal:

Advances in Medical Education and Practice

\author{
Nasser A N Alzerwi (iD \\ Department of Surgery, College of \\ Medicine, Majmaah University, Ministry of \\ Education, Al-Majmaah City, Riyadh \\ Region, Kingdom of Saudi Arabia
}

Purpose: A small number of researchers have proposed grit as a predictor of academic, nonacademic, and non-cognitive performance. However, no such studies have been conducted in the context of Saudi Arabian medical schools. The purpose of the present study is to examine the effect of grit on the academic performance of medical students in Majmaah University. Methods: Medical students of Majmaah University completed a survey in December 2019, answering questions on grit, personal characteristics, and academic performance.

Results: In the sample, the average grit score was moderately high $(\mathrm{M}=3.31$, standard deviation $=0.60)$. Female students' grit scores $(\mathrm{M}=3.47, \mathrm{SD}=0.56)$ were higher than those of males $(\mathrm{M}=3.22, \mathrm{SD}=0.61)(p=0.002)$. Of the academic performance variables, only the difference in mean grit score between those who repeated a year or more $(\mathrm{M}=3.11, \mathrm{SD}=$ $0.64)$ and non-repeaters $(\mathrm{M}=3.39, \mathrm{SD}=0.57)$ reflected a statistical significance $(p=0.001)$. Conclusion: The students who have repeated a year and more have lower grit scores. A follow-up study is required to compare the grit scores with the participants' ultimate completion status.

Keywords: academic performance, grit, medical students

\section{Introduction}

Traditional medical school selection processes emphasize applicants' academic and cognitive abilities rather than non-cognitive traits such as perseverance. ${ }^{1}$ Grit is a psychological construct which focuses on the individuals' persistent efforts and dedication for long-term goals. ${ }^{2-5}$ Grit levels, therefore, may reflect applicants' degree of commitment to achieving long-term goals, overcoming obstacles, effectively managing failure, and self-motivating even in the absence of extrinsic motivations. ${ }^{2,5,6}$ Grit levels are also known as significant predictors of both depression and well-being. ${ }^{7,8}$

Bakhsh $^{9}$ argued that the traditional model of selection results in high attrition rate among medical students. This has been shown to be especially true in the preclinical years. ${ }^{10}$ In a retrospective evaluation of the performance of medical students at King Faisal University, Dammam, Ibrahim et $\mathrm{al}^{10}$ found that students with high repetition rates experienced a $29.5 \%$ failure rate in biochemistry and a $14.2 \%$ failure rate in internal medicine. This potentially reflects the selective effect of the preclinical phase; the majority of students who drop out do so during this phase..$^{10}$ Debates on the quality and accuracy of the selection process have
Correspondence: Nasser A N Alzerwi Department of Surgery, College of Medicine, Majmaah University, Ministry of Education, P. O. Box 66, Al-Majmaah City, Riyadh Region I 1952, Kingdom of Saudi Arabia

Tel +96650670457 I

Fax +966164042022

Email n.alzerwi@mu.edu.sa 
covered the possibility of including tools that predict nonacademic and non-cognitive performance. Examples include assessment of applicants' ability to manage the stress of a condensed curriculum, persevere through adversity, resist distractions, and make the time commitments required to attain long-term goals. ${ }^{11,12}$

Currently, in Saudi Arabia, most selection protocols focus on academic and cognitive performance measures, including high school graduation grades, GPA, the Standard Achievement Admission Test, and unstructured interviews. ${ }^{13-15}$ The process ignores other measures that assess non-cognitive and non-academic performance of applicants, such as multiple mini-interviews, personal statement letters, recommendation letters, and personality tests. ${ }^{14}$ In the context of medical undergraduates in Saudi Arabia, no studies have assessed the grit levels in context with academic performance. Thus, as a step in assessing the impact of grit on the academic performance, we designed a survey study for medical students at Majmaah University. This study reports findings of this survey.

\section{Methods}

\section{Study Design}

\section{Participant Characteristics}

We administered a three-part online survey. Part one included participants' personal and demographic data. Part two focused on academic performance variables, including GPA scores, whether the student had repeated at least a year (repetition status), and, if a participant had repeated, the number of repeated years (number of years repeated), and whether the student had attended the Saudi Medical Licensure Examination (SMLE). Because research requires significant time and effort, and suggests a higher level of grit, questions addressing research experience, and whether students had been published, were also included. The third part of the survey administered a 12 -item Grit Score. ${ }^{5}$

\section{Grit}

In the 12-item Grit Survey ${ }^{5}$ I scored distraction-related items on a 5-point Likert scale from 1 (not at all like me) to 5 (very much like me). I reversed the coding for the section that questioned perseverance. I obtained the average score across all 12 items, with 5 being "extremely gritty" and 1 being "not gritty at all." The Grit Score had adequate reliability, with an internal consistency of Cronbach's alpha $(\alpha)=0.85 .^{5}$ There was also sufficient internal consistency in the investigative tool within the sample $(\alpha=0.82)$.

\section{Procedure}

The participants took 6-8 minutes, approximately, to complete the survey. A subjective report on participants' GPA determined academic performance. Further, I asked them whether they had repeated a year or more. This inquiry measured failure to pass a module and failure to pass multiple modules in a single year. I also asked participants about their SMLE status and publication status.

SMLE-eligible students, comprised mostly of interns, were divided into two groups based on whether they had attended the SMLE upon graduation or earlier, as sitting for the exam early in the academic year prior to one's internship is optional and reflects preparedness and readiness. Passing the SMLE with a high score is essential to attend top residency programs of the Saudi Committee for Health Specialties. Attaining a high percentage $(>90 \%)$ on the SMLE in the first attempt, early in the academic year, requires significant time and effort and can be considered to correlate with grit levels.

\section{Location and Duration of Study}

I conducted the study at Majmaah University, College of Medicine, from December 4-12, 2019.

\section{Ethical Approval and Patient Consent}

The Institutional Review Board at Majmaah University approved this study. In September 2019, during the first week of the academic year, I requested that group leaders of each academic year assist in recruiting medical students. I obtained informed consent documents from the participants.

\section{Inclusion and Exclusion Criteria}

Medical students attending Majmaah University during the 2019 academic year were eligible to participate. I excluded students who did not provide consent.

\section{Statistical Analysis and Software Used}

I conducted the analysis using SPSS 26 (IBM Corp. Armonk, NY, USA). Descriptive statistics determined the differences in average grit scores across student characteristics. "Kolmogorov-Smirnov" and "Shapiro-Wilk" Normality tests checked the normal distribution and homogeneity of variance assumptions. Since these were violated for all variables, I used non-parametric tests to compare different categories among different variables. Additionally, I conducted a Mann-Whitney $U$-test to determine whether there were 
Table I Participant Characteristics

\begin{tabular}{|c|c|c|c|c|c|c|c|c|c|}
\hline $\begin{array}{l}\text { Academic } \\
\text { Year }\end{array}$ & $\begin{array}{l}\text { No. of Students, } \\
\text { n (\%) }\end{array}$ & $\begin{array}{l}\text { Gender } \\
\mathrm{f} \% \\
\mathrm{~m} \%\end{array}$ & $\begin{array}{l}\text { Age } \\
\text { Mean (SD) }\end{array}$ & $\begin{array}{l}\text { High School } \\
\text { Graduation } \\
\text { Grade (\%) } \\
\text { Mean (SD) }\end{array}$ & $\begin{array}{l}\text { Medical } \\
\text { School } \\
\text { GPA } \\
\text { Mean (SD) }\end{array}$ & $\begin{array}{l}\text { Repeaters, } \\
\text { n(\%) }\end{array}$ & $\begin{array}{l}\text { Published } \\
\text { Research, } \\
\text { n(\%) }\end{array}$ & $\begin{array}{l}\text { Region } \\
\text { of } \\
\text { Origin } \\
\text { (\%) }\end{array}$ & $\begin{array}{l}\text { Grit } \\
\text { Score } \\
\text { Mean } \\
\text { (SD) }\end{array}$ \\
\hline \multirow{4}{*}{$\begin{array}{l}\text { Ist } \\
\text { Pre-clinical }\end{array}$} & \multirow[t]{4}{*}{$44(66.66)$} & \multirow[t]{2}{*}{ f 47.72} & \multirow[t]{2}{*}{$19.5(0.59)$} & \multirow[t]{2}{*}{$97.7(1.65)$} & \multirow[t]{2}{*}{$4.64(0.64)$} & \multirow[t]{2}{*}{ I (4.8) } & \multirow[t]{2}{*}{$2(9.5)$} & N 38.1 & \multirow{2}{*}{$\begin{array}{l}3.40 \\
(0.71)\end{array}$} \\
\hline & & & & & & & & 161.9 & \\
\hline & & \multirow[t]{2}{*}{ m 52.27} & \multirow[t]{2}{*}{$19.5(0.73)$} & \multirow[t]{2}{*}{$96.5(2.84)$} & \multirow[t]{2}{*}{$4.66(0.33)$} & \multirow[t]{2}{*}{$4(17.4)$} & \multirow[t]{2}{*}{ I (4.3) } & N 39.1 & \multirow{2}{*}{$\begin{array}{l}3.06 \\
(0.75)\end{array}$} \\
\hline & & & & & & & & 160.9 & \\
\hline \multirow{4}{*}{$\begin{array}{l}\text { 2nd } \\
\text { Pre-clinical }\end{array}$} & \multirow[t]{4}{*}{$50(83.33)$} & \multirow[t]{2}{*}{ f 36} & \multirow[t]{2}{*}{$20.5(1.09)$} & \multirow[t]{2}{*}{97.8 (1.79) } & \multirow[t]{2}{*}{$3.66(0.59)$} & \multirow[t]{2}{*}{$10(55.6)$} & \multirow[t]{2}{*}{$0(0.0)$} & N 50 & \multirow{2}{*}{$\begin{array}{l}3.64 \\
(0.52)\end{array}$} \\
\hline & & & & & & & & 150 & \\
\hline & & \multirow[t]{2}{*}{ m 64} & \multirow[t]{2}{*}{$21.5(1.41)$} & \multirow[t]{2}{*}{$97.5(2.17)$} & \multirow[t]{2}{*}{$3.78(0.57)$} & $13(40.6)$ & $7(21.9)$ & N 18.8 & 3.18 \\
\hline & & & & & & & & | 81.2 & $(0.50)$ \\
\hline Ist & $42(67.74)$ & $f 38.10$ & $21.9(0.77)$ & $97.9(1.30)$ & $3.74(0.72)$ & $8(50)$ & I (6.3) & N 75 & 3.38 \\
\hline $\begin{array}{l}\text { Clinical } \\
\text { disciplines }\end{array}$ & & & & & & & & 125 & $(0.45)$ \\
\hline & & m 61.90 & $21.9(1.31)$ & $97.6(2.13)$ & $3.68(0.73)$ & $10(38.5)$ & $4(15.3)$ & N 34.6 & 3.26 \\
\hline & & & & & & & & 165.4 & $(0.48)$ \\
\hline 2 nd & $35(59.32)$ & f 14.29 & $21.8(0.44)$ & $98.5(0.86)$ & $4.07(0.58)$ & $0(0.0)$ & I (20.0) & N 60 & 3.57 \\
\hline $\begin{array}{l}\text { Clinical } \\
\text { disciplines }\end{array}$ & & & & & & & & 140 & $(0.52)$ \\
\hline & & m 85.71 & $23.5(1.16)$ & $97.9(0.77)$ & $3.45(0.66)$ & $18(60.0)$ & $17(56.6)$ & $N 13.3$ & 3.03 \\
\hline & & & & & & & & 186.7 & $(0.73)$ \\
\hline $3 r d$ & $35(100)$ & f 25.7 I & $23.0(0.70)$ & $97.2(1.82)$ & $3.86(0.45)$ & $0(0.0)$ & $0(0.0)$ & N 55.6 & 3.53 \\
\hline $\begin{array}{l}\text { Clinical } \\
\text { disciplines }\end{array}$ & & & & & & & & I 44.4 & $(0.33)$ \\
\hline & & m 74.29 & $23.6(0.98)$ & $96.8(2.38)$ & $3.57(0.55)$ & $5(19.2)$ & $14(53.8)$ & N 38.5 & 3.47 \\
\hline & & & & & & & & 161.5 & $(0.60)$ \\
\hline Internship & $48(87.27)$ & f 31.25 & $24.2(0.77)$ & $98.5(1.17)$ & $4.04(0.32)$ & $0(0.0)$ & $13(86.6)$ & N 60 & 3.41 \\
\hline & & & & & & & & 140 & $(0.63)$ \\
\hline & & m 68.75 & $24.6(0.99)$ & $97.7(1.48)$ & $3.49(0.58)$ & $9(27.3)$ & $22(66.8)$ & $N 15.2$ & 3.35 \\
\hline & & & & & & & & | 84.8 & $(0.54)$ \\
\hline Total & $254(75.37)$ & f 33.1 & $21.5(1.82)$ & $97.9(1.54)$ & $4.04(0.68)$ & $19(22.6)$ & $17(20.2)$ & N 54.8 & 3.47 \\
\hline & & & & & & & & 145.2 & $(0.56)$ \\
\hline & & $\mathrm{m} 66.9$ & $22.6(1.97)$ & $97.4(2.04)$ & $3.74(0.69)$ & 59 (34.7) & $65(38.2)$ & N 25.3 & 3.22 \\
\hline & & & & & & & & 174.7 & $(0.61)$ \\
\hline & & & $22.2(1.98)$ & $97.6(1.90)$ & $3.84(0.70)$ & 78 (30.7) & $82(32.3)$ & N 35.0 & 3.31 \\
\hline & & & & & & & & 165.0 & $(0.60)$ \\
\hline
\end{tabular}

Abbreviations: f, female; m, male; SD, standard deviation; GPA, grade points average; N, native to Majmaah city; I, immigrant (non-native) to Majmaah city; \#n, number.

differences in grit scores among students due to their characteristics (gender, native or non-native to Majmaah) and academic performance determinants (publication, repetition status, number of years repeated, and SMLE status). By conducting Kruskal-Wallis tests, I determined whether there were statistically significant differences for the 
following categories: age, high school graduation grades, and curricular phases by age, GPA, GPA rank, publication status, and grit score. Whenever there was a significant difference between categories (GPA between curricular phases categories, repetition status categories between curricular phases, and number of years repeated among different GPA ranks), I conducted the Games-Howell Post hoc test. Using Pearson's Product-Moment Correlation Coefficient, I determined if there was a correlational relationship between grit score and academic performance in terms of GPA and between grit score and age.

\section{Results}

\section{Participant Characteristics}

Of the 254 medical students who participated in this study (Table 1), 170 (66.9\%) students were male and 84 (33.1\%) were female. Although the majority had not repeated an academic year $(69.3 \%, \mathrm{n}=176)$, approximately one-third had repeated one academic year or more $(30.7 \%, \mathrm{n}=78)$. The average age was $22.2(\mathrm{SD}=1.98)$. The majority of students were non-native to Majmaah City $(n=165,65.0 \%)$, while the rest identified as natives $(n=89,35.0 \%)$. An overall $75.4 \%$ of the total medical school population participated. There were no differences between participants and nonparticipants in terms of variables used to assess academic success, including GPA, repetition status, numbers of year repeated, publication, and SMLE status $(p>0.05)$.

\section{Grit Related to Participant}

\section{Characteristics and Academic}

\section{Performance}

The mean grit score was $3.31(\mathrm{SD}=0.60)$, with a range of 1.00 to 4.83 . I identified significant differences between the grit scores for gender and repeat status (Table 2). I found no significance in high school graduation grades, GPA, publication status, region of origin, SMLE status, or

Table 2 Grit Score Based on Gender and Repetition Status

\begin{tabular}{|l|l|l|l|}
\hline Variable & $\begin{array}{l}\text { Categories, } \\
\text { n (\%) }\end{array}$ & $\begin{array}{l}\text { Grit Score } \\
\text { Mean (SD) }\end{array}$ & P \\
\hline Gender & f & $3.47(0.56)$ & $0.002^{*}$ \\
\hline Repetition status & $\begin{array}{l}\text { No } \\
\text { Yes }\end{array}$ & $3.22(0.6 \mathrm{I})$ & $3.11(0.57)$ \\
\hline
\end{tabular}

Note: *Statistically significant P-value $<0.05$.

Abbreviations: $\mathrm{f}$, female; $\mathrm{m}$, male; $\mathrm{SD}$, standard deviation; $P$, probability value.
Table 3 GPA Based on Published and Non-Published Status, High School Graduation Grade, Gender, Region of Origin, Repetition Status, and Curricular Phase

\begin{tabular}{|c|c|c|c|}
\hline Variable & Categories & $\begin{array}{l}\text { GPA Mean } \\
\text { (SD) }\end{array}$ & $\mathbf{P}$ \\
\hline \multirow[t]{2}{*}{ Publication } & $\begin{array}{l}\text { Non- } \\
\text { published }\end{array}$ & $3.95(0.70)$ & \multirow[t]{2}{*}{$0.00 I^{*}$} \\
\hline & Published & $3.6 I(0.65)$ & \\
\hline \multirow{2}{*}{$\begin{array}{l}\text { High school graduation } \\
\text { grade }\end{array}$} & $90-95 \%$ & $4.04(0.70)$ & \multirow[t]{2}{*}{0.15} \\
\hline & $95.1-100 \%$ & $3.8 \mathrm{I}(0.70)$ & \\
\hline \multirow[t]{2}{*}{ Gender } & $f$ & $4.04(0.68)$ & \multirow[t]{2}{*}{$0.001 *$} \\
\hline & $\mathrm{m}$ & $3.74(0.69)$ & \\
\hline \multirow[t]{2}{*}{ Region of origin } & $\mathrm{N}$ & $3.96(0.68)$ & \multirow[t]{2}{*}{$0.037^{*}$} \\
\hline & I & $3.77(0.70)$ & \\
\hline \multirow[t]{2}{*}{ Repetition status } & No & $4.09(0.58)$ & \multirow{2}{*}{$\begin{array}{l}< \\
0.001 *\end{array}$} \\
\hline & Yes & $3.27(0.62)$ & \\
\hline \multirow[t]{3}{*}{ Curricular phase } & Preclinical & $4.17(0.7 I)$ & \multirow{3}{*}{$\begin{array}{l}< \\
0.001 *\end{array}$} \\
\hline & Clinical & $3.64(0.65)$ & \\
\hline & Internship & $3.66(0.57)$ & \\
\hline
\end{tabular}

Note: *Statistically significant P-value $<0.05$.

Abbreviations: $S D$, standard deviation; $f$, female; $m$, male; $P$, probability value; GPA, grade points average; N, native to Majmaah city; I, immigrant (non-native) to Majmaah city.

curricular phase. Additionally, there was no significant relationship between age and grit score $(r=-0.077, p=$ 0.22). Albeit weak, there was positive statistical correlation between GPA and grit score $(r=0.142, p=0.02)$.

\section{GPA and Number of Years Repeated Related to Participant's Characteristics and Academic Performance}

Significant differences were identified for GPA scores between repetition status categories (number of repeaters vs number of non-repeaters) and for number of years repeated based on publication status, gender, region of origin, curricular phase, and GPA ranks. However, differences based on high school graduation grades were negligible (Tables 3 and 4).

\section{Comparison of Publication Status, High School Graduation Grades, and Age According to Gender}

There was statistical significance between male and female students with regard to number of published articles $(0.71$, 
Table 4 Number of Years Repeated Based on Curricular Phase, High School Graduation Grade, GPA Rank, and Gender

\begin{tabular}{|c|c|c|c|}
\hline Variable & Categories & $\begin{array}{l}\text { Number of Years } \\
\text { Repeated } \\
\text { Mean (SD) }\end{array}$ & $P$ \\
\hline \multirow[t]{3}{*}{ Curricular phase } & Preclinical & $1.33(0.57)$ & \multirow[t]{3}{*}{0.05} \\
\hline & Clinical & $1.56(0.94)$ & \\
\hline & Internship & $1.23(0.52)$ & \\
\hline \multirow{2}{*}{$\begin{array}{l}\text { High school } \\
\text { graduation grade \% }\end{array}$} & $90-95$ & 1.65 (1.09) & \multirow[t]{2}{*}{0.14} \\
\hline & $95.1-100$ & $1.38(0.70)$ & \\
\hline \multirow[t]{2}{*}{ Gender } & $f$ & $1.27(0.58)$ & \multirow[t]{2}{*}{$0.04 *$} \\
\hline & $\mathrm{m}$ & $1.48(0.82)$ & \\
\hline \multirow[t]{4}{*}{ GPA $(0.00 / 5)$} & $\begin{array}{l}\text { 2.0-3.0: } \\
\text { Poor }\end{array}$ & $2.36(0.89)$ & \multirow[t]{4}{*}{$<0.00 I^{*}$} \\
\hline & $\begin{array}{l}\text { 3.0-4.0: } \\
\text { Good }\end{array}$ & $1.48(0.78)$ & \\
\hline & $\begin{array}{l}\text { 4.0-4.5: } \\
\text { Very Good }\end{array}$ & $1.02(0.14)$ & \\
\hline & $\begin{array}{l}4.5-5: \\
\text { Excellent }\end{array}$ & $1.05(0.23)$ & \\
\hline
\end{tabular}

Note: *Statistically significant $P$-value $<0.05$.

Abbreviations: SD, standard deviation; $n$, number of participants; GPA, grade points average; $\mathrm{f}$, female; $\mathrm{m}$, male; $P$, probability value.

$\mathrm{SD}=1.28$ for male, compared with $0.35, \mathrm{SD}=0.95$ for female, $p=0.004)$, high school graduation grades $(97.4 \%$ $\mathrm{SD}=2.05$ for male compared with $97.9 \%, \mathrm{SD}=1.54$ for female, $p=0.03)$, and age (22.6, $\mathrm{SD}=1.98$ for male, compared with 21.6, $\mathrm{SD}=1.82$ for female, $p<0.001$ ) (Table 5).

\section{Discussion}

Medical study demands long-term commitment, goal setting and time management skills, perseverance, and focus. Admission to medical schools in Saudi Arabia is highly competitive; only the top $10 \%$ of high school graduates are eligible for application. ${ }^{13}$ The selection process is fair and rigorous to ensure admission of students with the highest cognitive and academic performance; these students are more likely to complete the curriculum without failure or repetition. ${ }^{16}$ Furthermore, non-cognitive and personal traits are significant predictors of clinical performance, decision-making, and interpersonal skills, which are just as crucial as cognitive skills. ${ }^{17,18}$

The results of the study indicated average-level grit scores among medical students. In a study of 62 third-
Table 5 Publication Status, High School Graduation Grade, and Age According to Gender

\begin{tabular}{|l|l|l|}
\hline Variable & Gender: Mean (SD) & P \\
\hline \multirow{2}{*}{ High school graduation grade \% } & m: $97.4(2.05)$ & \multirow{2}{*}{$0.03^{*}$} \\
\cline { 2 - 2 } & f: $97.9(1.54)$ & \\
\hline \multirow{2}{*}{ Age } & m: $22.58(1.98)$ & \multirow{2}{*}{$<0.00 I^{*}$} \\
\cline { 2 - 2 } & f: $21.6(1.82)$ & \\
\hline \multirow{2}{*}{ Number of publications } & m: $0.71(1.28)$ & \multirow{2}{*}{$0.004^{*}$} \\
\cline { 2 - 2 } & f: $0.35(0.95)$ & \\
\hline
\end{tabular}

Note: *Statistically significant P-value $<0.05$.

Abbreviations: SD, standard deviation; f, female; $m$, male; $P$, probability value.

year medical students Cortez et $\mathrm{al}^{19}$ reported a comparable range of grit scores of $3.51 \pm 0.58$. The grit score observed in this study is also within the average of 4.01 that MillerMatero et $\mathrm{al}^{6}$ reported in their study of 130 graduating students. In the present study, female students presented significantly higher grit scores than males, deviating from studies that identified negligible differences. ${ }^{6,20}$ Female students, in our study group, were significantly younger, had higher high school graduation grades, and fewer published studies, potentially indicating the existence of systemic factors that make female students grittier and better academic achievers than their male counterparts. Importantly, there was no statistically significant correlation between age and grit scores, contrasting with the conclusion of the original study by Duckworth et al, ${ }^{5}$ that found that grit scores tended to increase with age when education is controlled for.

Although there was no significant difference in grit scores between curricular phases, a statistically significant difference between curricular phases in terms of number of years repeated might reflect the varying difficulty between preclinical and clinical phases. The clinical phase is a traditional discipline-based curriculum; in contrast, the preclinical phase is a problem-based curriculum. This finding might suggest that the clinical phase, which is geared toward summative clinical assessments that emphasize individuals' clinical application of knowledge, requires more effort and time than the preclinical phase, which is geared toward continuous and formative assessment of team-based performance and emphasizes knowledge recall and theoretical application of knowledge to clinical scenarios. The statistical significance for differences in GPA scores between the preclinical phase and clinical phase, 
and between the preclinical and internship phase supports this finding; however, there was no statistically significant difference between the clinical and internship phases.

There was no statistical significance for the difference in grit scores between published and non-published students, though students with higher GPA tend to have higher grit. This suggests that students with better academic performance tended to participate less in research compared to students with lower academic performance. The findings could indicate that students with a lower GPA tend to compensate by increasing research engagement to gain points for the matching program. In contrast, students with a higher GPA decided to invest all their time in securing it; GPA carries the highest weight in the Saudi Committee for Health Specialties Matching Program.

One of the important finding is that the grit score was higher in the students who completed curriculum without repetition. In a study by Halliday et $\mathrm{al}^{21}$ grit score was found to have a weak correlation with the burnout among UK doctors. ${ }^{21}$ The authors recommended to improve grit through resilience training. Consideration of the fact that the burnout is a serious challenge that requires urgent attention, potential of grit-based interventions needs to be explored. The results of this study, in light of the recommendations made by Halliday et al, ${ }^{21}$ highlight the possibility of considering grit score as a factor in the remediation efforts to help students who have repeated a year in college. There was no significance in the differences between grit scores for those who sat for the SMLE exam and those who did not. This could be due to the small size of the SMLE eligible group. Consequently, the small SMLE eligible group size could be due to the timing of the survey being administered at the beginning of the academic year.

This is the first study reporting grit scores and other associated factors among medical students in Saudi Arabia. The findings of this work will raise awareness about this important aspect among medical colleges in the country and may act as a precursor to a nation wide study.

This study has certain limitations. First is the fact that it is a single-center study; therefore, findings of it cannot be generalized. Nation-wide multicenter studies should be conducted in future to test the wider validity of the results of this study. Furthermore, there is a possibility of confounders that might influence the grit score of students who repeated a year or more. A multivariable modeling on a large pool of nation-wide dataset may clarify the impact of grit more effectively. Additionally, grit scores are partially based on subjective, self-reported data; the potential exists for students to inflate their scores for social desirability bias. ${ }^{4}$ This opens a new field of inquiry on how to guard against such inflations and ensure the robustness of this measure. Additionally, this study did not consider students' socio-economic background or their parents' level of education, which could affect grit level. Furthermore, this study excluded various high school performance standardized tests, including the General Aptitude Test and the Standard Achievement and Admission Test, which are a part of the selection criteria for medical school admission. These could potentially more accurately predict high school graduates' performance in medical school. Since these excluded tests could have a stronger correlation to grit scores than high school graduation grades, future research studies should address the appropriateness of such tests for medical student selection in Saudi Arabia. ${ }^{22,23}$ After testing for measures at other undergraduate schools, future research should extend this study to postgraduate trainees in different specialties to discern whether grit score predicts acceptance - and successful completion of - various residency programs. Moreover, this study could evolve into a longitudinal study of a preclinical cohort through graduation to determine whether their grit scores change as students mature.

\section{Conclusion}

At Majmaah University, the medical students have average levels of grit, with female students possessing higher grit levels than their male counterparts. Grit score was also higher in students completing medical school without repeating an academic year. Higher grit scores therefore might be associated with lack of repetition of one or more years among the students, although a multi-center follow-up study would be required to compare the grit scores with the participants' ultimate completion status after correcting for possible confounding effects. Future research should explore whether grit scores change after graduation, and consider whether the score predicts successful completion of postgraduate residency programs for determining its inclusion in the selection methods for postgraduate training.

\section{Acknowledgments}

Thank you to Dr. Abdulaziz Alhindi MD, Dr. Suliman Almutairi MD, Dr. Bandar Idrees MD, Dr. Suliman Alshaikh MD, and Dr. Ahmad Alhumaid MD, for their assistance with 
preparing and proofreading this manuscript, also many thanks to Editage.com for their help in language editing.

\section{Ethics and Consent Statement}

Ethics approval was obtained from the Institutional Review Board at Majmaah University. Written informed consent documents were obtained from all participants.

\section{Disclosure}

The author reports no conflicts of interest in this work.

\section{References}

1. Farruggia S, Han C-W, Watson L, Moss T, Bottoms B. Noncognitive factors and college student success. J Coll Stud Retention Res Theory Pract. 2018;20(308-327):308-327. doi:10.1177/1521025116666539

2. Duckworth AL, Peterson C, Matthews MD, Kelly DR. Grit: perseverance and passion for long-term goals. J Pers Soc Psychol. 2007;92 (6):1087-1101. doi:10.1037/0022-3514.92.6.1087

3. Giordano M. Grit and intrinsic motivation for language learning: instrument validation using the Rasch model. Shiken. 2019;23:28-42.

4. Eskreis-Winkler L, Duckworth A, Shulman E, Beal S. The grit effect: predicting retention in the military, the workplace, school and marriage. Front Psychol. 2014;5:36.

5. Duckworth AL, Quinn PD. Development and validation of the short grit scale (grit-s). J Pers Assess. 2009;91(2):166-174. doi:10.1080/ 00223890802634290

6. Miller-Matero LR, Martinez S, MacLean L, Yaremchuk K, Ko AB. Grit: a predictor of medical student performance. Educ Health. 2018;31(2):109-113. doi:10.4103/efh.EfH_152_16

7. Salles A, Lin D, Liebert C, et al. Grit as a predictor of risk of attrition in surgical residency. Am J Surg. 2017;213(2):288-291. doi:10.1016/j. amjsurg.2016.10.012

8. Burkhart RA, Tholey RM, Guinto D, Yeo CJ, Chojnacki KA. Grit: a marker of residents at risk for attrition? Surgery. 2014;155 (6):1014-1022. doi:10.1016/j.surg.2014.01.015

9. Bakhsh TM. Attrition rate at a faculty of medicine in Western Saudi Arabia. J King Abdulaziz Univ Med Sci. 2004;11:99-104. doi:10.4197/ Med.11-1.11
10. Ibrahim EM, Al-Freihi HM, Rihan TI, Al-Sohaibani MO. Comparative study of students' performance at premedical, preclinical, and clinical levels in a medical school. Ann Saudi Med. 1988;8 (6):481-484.

11. Lazin R, Neumann L. Student characteristics as predictors of drop-out from medical school: admissions to Beer-Sheva over a decade. Med Educ. 1991;25(5):396-404. doi:10.1111/j.1365-2923. 1991.tb00087.x

12. Powis DA. Selecting medical students. Med Educ. 1994;28 (5):443-469. doi:10.1111/j.1365-2923.1994.tb02555.x

13. Al-Sulaiman AA. Saudi medical education: challenges in the new millennium. J Family Community Med. 2000;7(1):15-20.

14. Abdulrazzaq YM, Qayed KI. Could final year school grades suffice as a predictor for future performance? Med Teach. 1993;15(2-3):243-251. doi:10.3109/01421599309006718

15. Telmesani A, Zaini RG, Ghazi HO. Medical education in Saudi Arabia: a review of recent developments and future challenges. East Mediterr Health J. 2011;17(8):703-707.

16. Murden R, Galloway GM, Reid JC, Colwill JM. Academic and personal predictors of clinical success in medical school. $J$ Med Educ. 1978;53(9):711-719. doi:10.1097/00001888-197809000-00001

17. Westin S, Salvesen K, Götestam KG. Problem-solving styles of medical students related to knowledge and personality in simulated clinical situations. Med Educ. 1986;20(2):109-116. doi:10.1111/ j.1365-2923.1986.tb01056.x

18. Willoughby TL, Gammon LC, Jonas HS. Correlates of clinical performance during medical school. J Med Educ. 1979;54(6):453-460. doi:10.1097/00001888-197906000-00002

19. Cortez AR, Winer LK, Kim Y, Hanseman DJ, Athota KP, Quillin RC 3rd. Predictors of medical student success on the surgery clerkship. Am J Surg. 2019;217(1):169-174. doi:10.1016/j.amjsurg.2018.09.021

20. Credé M, Tynan MC, Harms PD. Much ado about grit: a meta-analytic synthesis of the grit literature. J Pers Soc Psychol. 2017;113(3):492-511. doi:10.1037/pspp0000102

21. Halliday L, Walker A, Vig S, Hines J, Brecknell J. Grit and burnout in UK doctors: a cross-sectional study across specialties and stages of training. Postgrad Med J. 2017;93(1101):389-394. doi:10.1136/postgradmedj-2015-133919

22. Albishri JA, Aly SM, Alnemary Y. Admission criteria to Saudi medical schools. Which is the best predictor for successful achievement? Saudi Med J. 2012;33(11):1222-1226.

23. Murshid K. The predictive value of individual admission criteria on academic performance in a Saudi medical college. J Taibah Univ Med Sci. 2013;8(1):18-23. doi:10.1016/j.jtumed.2013.01.005

\section{Publish your work in this journal}

Advances in Medical Education and Practice is an international, peerreviewed, open access journal that aims to present and publish research on Medical Education covering medical, dental, nursing and allied health care professional education. The journal covers undergraduate education, postgraduate training and continuing medical education including emerging trends and innovative models linking education, research, and health care services. The manuscript management system is completely online and includes a very quick and fair peer-review system. Visit http://www.dovepress.com/testimonials.php to read real quotes from published authors. 